\title{
Fenugreek-mediated synthesis of zinc oxide nanoparticles and evaluation of its in vitro and in vivo antitumor potency
}

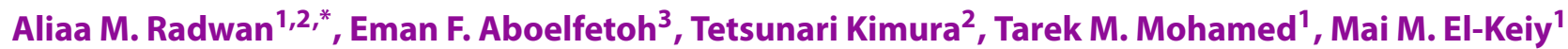

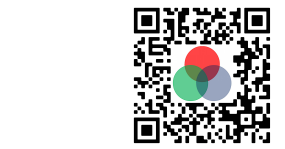

Use your smartphone to scan this QR code and download this article

${ }^{1}$ Biochemistry Division, Chemistry Department, Faculty of Science, Tanta University, Tanta, 31527, Egypt

${ }^{2}$ Department of Chemistry, Graduate School of Science, Kobe University, Nada-Ku, Kobe, Hyogo, 657-8501, Japan

${ }^{3}$ Chemistry Department, Faculty of Science, Tanta University, Tanta, 31527, Egypt

\section{Correspondence}

Aliaa M. Radwan, Biochemistry Division, Chemistry Department, Faculty of Science, Tanta University, Tanta, 31527, Egypt

Department of Chemistry, Graduate School of Science, Kobe University, Nada-Ku, Kobe, Hyogo, 657-8501, Japan Email:

alyaa_radwan@science.tanta.edu.eg

History

- Received: May 28, 2021

- Accepted: Aug 07, 2021

- Published: Aug 28, 2021

DOI : 10.15419/bmrat.v8i8.687

\section{Check for updates}

\section{Copyright}

(c) Biomedpress. This is an openaccess article distributed under the terms of the Creative Commons Attribution 4.0 International license.

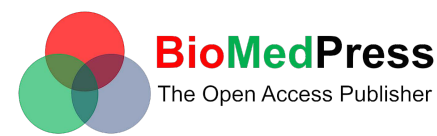

\begin{abstract}
Introduction: Zinc oxide nanoparticles (ZnONPs) are one of the most interesting metal oxide nanoparticles due to their easy functionalization, biocompatibility, and anticancer impact. The current study was designated to evaluate the in vitro and in vivo anticancer potency of biologically synthesized ZnONPs. Methods: Fenugreek seeds' extract was used to prepare ZnONPs, and then characterized by scanning electron microscope (SEM), energy dispersive X-ray (EDX), X-ray diffraction (XRD), UV-V spectroscopy and transmission electron microscope (TEM). The in vitro antitumor activity of biogenic ZnONPs against different cancer cells was evaluated by MTT assay. In addition, their anticancer activities alone or in combination with Doxorubicin were investigated against EAC model using intraperitoneal injection day after day. Results: Biologically synthesized ZnONPs showed a cytotoxic potency against different cancer cell lines combined with lower toxicity against normal cells. Further, the in vivo study revealed that the treatment by ZnONPs alone or combined with doxorubicin hampered the proliferation of EAC in mice by lowering the ascetic volume and the number of viable tumor cells. Moreover, ZnONPs alone or combined with doxorubicin induced the cell cycle arrest at G0/G1 phase and apoptosis by up-regulating the expression of caspase-3 and Bax and down-regulating the expression of $\mathrm{BCl}-2$ proteins. Conclusion: Our study indicated that the biogenic ZnONPs could be instructive to future cancer treatment research.
\end{abstract}

Key words: Cell cycle, Ehrlich ascites carcinoma, Fenugreek seeds extract, Zinc oxide nanoparticles

\section{INTRODUCTION}

The chemotherapeutic drugs are considered as the primary option for different malignant tumors. These anticancer agents are designated to simply kill the cancer cells in a non-specific manner, leading to its distribution and accumulation in healthy tissues and resulting in undesirable and severe side effects ${ }^{1}$. Therefore, novel treatment approaches have been employed to minimize the severity of side effects such as nanotechnology. Nanotechnology has introduced nanoparticle systems for cancer treatment, which have the ability to selectively eradicate the cancer cells and at the same time save the normal cells from the drug toxicity ${ }^{2}$.

Zinc oxide nanoparticles ( $\mathrm{ZnONPs}$ ) are one of the most important inorganic metal oxide nanoparticles, which are employed in different biomedical applications such as cancer therapy due to its impressive properties, nontoxicity and biocompatibility ${ }^{3}$. Despite there being many approaches used in the manufacture of $\mathrm{ZnO}$ nanostructure, they are related to certain constraints such as toxic chemicals, high operating costs and energy needs ${ }^{4}$. Therefore, replacing these approaches with simple, cost-effective and environmentally sustainable systems is becoming increas- ingly important. The green synthesis of $\mathrm{ZnONPs}$ using natural plant extracts attracted the attention of the researchers because plant-mediated synthesis is environmentally friendly, inexpensive, readily available, yields the highest quantity of NPs and has a wide range of metabolites to help effectively produce and cap NPs ${ }^{5}$.

Fenugreek seed (Trigonella foenum graecum) is an annual plant belonging to the family of Leguminosae. Such seeds have therapeutic properties for anorexia, antidiabetic, hepatoprotective influence, anticancerial, antibacterial and gastric stimulant. Fenugreek seeds contain various components such as diosgenin, saponin, coumarin, a variety of alkaloids such astrigonellin, gentianin and carpaine, polyphenol compounds such as rhaponticin and isovitexin, and flavonoids ${ }^{6}$. Such biomolecules contain different functional groups capable of forming nanoparticles. The resulting nanoparticles are then safe against further reactions and aggregations, which increases its steadiness. Previous studies suggested that fenugreek seeds extract is rich in galactomannan polysaccharides that have reducing functional groups which may have an important role in nanoparticles preparation, in addition to, containing phenolic compounds that may act as capping and stabilizing agents 
for the prepared nanoparticles ${ }^{7}$. The objective of this study is to introduce a new and simple green synthesis method for preparing the nanostructure of $\mathrm{ZnO}$ using fenugreek extract as a reducing agent and an effective stabilizer, rather than using harmful, reducing and costly stabilizing agents such as surfactants and polymers, and investigating their potential anticancer activity in vitro against various lines of cancer cells and in vivo using Ehrlich ascites carcinoma model.

\section{METHODS}

\section{Materials}

Fenugreek seeds (Giza 1, Egyptian cultivar) were purchased from the local market of Tanta, Egypt. Ethanol, sodium hydroxide and zinc nitrate. $6 \mathrm{H}_{2} \mathrm{O}$ were purchased from El-Nasr pharmaceutical chemicals company, Egypt. 3(4,5dimethylthiazol-2-yl)-2,5-diphenyltetrazolium bromide (MTT), Trichloroacetic acid (TCA), Thiobarbituric acid (TBA), 5,5'- dithiobis 2- nitrobenzoic acid (DTNB), 1-chloro-2,4 dinitrobenzene (CDNB) and reduced glutathione (GSH) were purchased from Thermo Fisher, Germany. Adricin (doxorubicin, $2 \mathrm{mg} / \mathrm{mL}$ ) was obtained from EIMC United Pharmaceutics, Cairo, Egypt. All other chemicals were obtained in analytical grades.

\section{Experiments}

\section{Preparation of Fenugreek Extract}

The fenugreek seeds were used for the preparation of $5 \%$ aqueous extract according to the method of Ramamurthy with some modifications ${ }^{7}$. The mixture was boiled for 30 minutes on a magnetic stirrer and filtered to eliminate the unwanted residue after cooling using the Whatman filter paper, and the clear supernatant extract was used for the synthesis of 3D hierarchical flower-like nanostructure of $\mathrm{ZnO}$.

\section{Synthesis of ZnO Nanoparticles}

Zinc oxide nanoparticles were prepared with some modifications in the methods ${ }^{8,9}$. In brief, $20 \mathrm{~mL}$ of fenugreek aqueous extract was added dropwise to 80 $\mathrm{mL} \mathrm{Zn}\left(\mathrm{NO}_{3}\right)_{2}$. $6 \mathrm{H}_{2} \mathrm{O}(0.025 \mathrm{M})$ under continuous vigorous stirring at room temperature for 1 hour. The $\mathrm{pH}$ of the mixture was subsequently converted to 12 using $\mathrm{NaOH}(2 \mathrm{M})$ with continuous stirring for another 1 hour. This yielded a yellowish-white solution. A white $\mathrm{ZnO}$ powder was separated by centrifugation at $10000 \mathrm{rpm}$ for 20 minutes, washed with doubly distilled $\mathrm{H}_{2} \mathrm{O}$, then with absolute ethanol three times to eliminate the impurities, dried in oven at $60{ }^{\circ} \mathrm{C}$ overnight, and collected for characterization.

\section{Characterization of ZnO Nanoparticles}

The crystalline size and phase identity of synthesized ZnONPs were characterized by a GNR-X-ray diffractometer (APD $2000 \mathrm{PRO}$ ) with $\mathrm{Cu}-\mathrm{K} \alpha$ radiation (Voltage $=40 \mathrm{kV}$, Current $=30 \mathrm{~mA}, \lambda=1.5406$, scan rate of $2 \mathrm{~min}^{-1}$ and scan range of $2 \theta$ from 10 $\left.-90^{\circ}\right)^{10}$. Using the PerkinElmer spectrophotometer, the $\mathrm{KBr}$ technique was employed to check the Fourier transform infrared (FTIR) spectra in which the dried sample was grounded to powder with a mesh sieve and mixed 1/1 with vacuum dried $\mathrm{KBr}$ powder to make a compressed pellet with subsequent recording of infrared spectrum ${ }^{11}$. The surface morphology of samples was studied by transmission electron microscope (TEM), JEOL-TEM "100-SX" and scanning electron microscope (SEM), JeoL-JSM- $6510 \mathrm{TV}^{12}$. The UV-Vis absorption spectrum of the sample was measured using the Shimadzu 2100S UV-Vis spectrophotometer (Japan) with a $1.0-\mathrm{cm}$-path length cell. Sample suspension was prepared by dispersing $1 \mathrm{mg}$ of ZnONPs in $1 \mathrm{ml}$ absolute ethanol by sonication, then diluted 20 times and absolute ethanol was used as a blank ${ }^{13,14}$. The composition of elements such as $\mathrm{Zn}$ and $\mathrm{O}$ was verified by a dispersive energy $\mathrm{X}$-ray spec$\operatorname{tra}(\mathrm{EDX})^{15}$.

\section{In Vitro study of ZnO nanoparticles}

\section{Cell Line and Culture Condition}

Four different types of cancer cells (EAC, MCF-7, HCT-116 and HepG2) and normal cells (WISH)were used to study the cell anticancer activity and cytotoxicity against ZnONPs. The cells were purchased from the cell culture department, VACSERA (Cairo, Egypt) and cultured according to the standard protocol. The HCT-116, EAC and WISH cells were grown in RPMI-1640, while MCF-7 and HepG-2 cells were grown in DMEM medium (Dulbecco's Modified Eagle Medium) supplemented with $10 \%$ fetal bovine serum and penicillin/streptomycin (100 units/mL) (Cambrex Bio Science Verviers, Belgium). All cells were maintained at $37^{\circ} \mathrm{C}$ in a $5 \% \mathrm{CO}_{2}$ humidified incubator.

\section{Cell Viability Assay}

The cytotoxicity of the green synthesized ZnONPs was assessed by 3-(4, 5-di Methyl Thiazol-2-yl) 2,5diphenyl Tetra-zolium bromide (MTT) assay. In brief, the cells were seeded into 96-well plates at density $1 \times 10^{4}$ cells/well $\left(1 \times 10^{5}\right.$ cells $\left./ \mathrm{mL}\right)$ and incubated at $37{ }^{\circ} \mathrm{C}$ in a $\mathrm{CO}_{2}$ incubator to develop a complete monolayer sheet. After 24 hours, the cells were subjected to treatment with different concentrations of 
ZnONPs and doxorubicin $(5-100 \mu \mathrm{g} / \mathrm{mL})$, and incubated for an additional 48 hours. The wells containing medium without drug were served as control, and triplicates were maintained for all concentrations. After the incubation, $200 \mu \mathrm{L}$ of $0.5 \mathrm{mg} / \mathrm{mL} 3-(4$, 5-di Methyl Thiazol-2-yl) 2,5-diphenyl Tetra-zolium bromide (MTT) (Sigma-Aldrich, USA) was added to each well and incubated in 5\% $\mathrm{CO}_{2}$ incubator for 4 hours. The formazan crystals of MTT reduction were solubilized in dimethylsulfoxide (DMSO) and then the absorbance was measured at $570 \mathrm{~nm}$ using microplate ELISA reader ${ }^{16}$.

\section{In Vivo Antitumor Activity of ZnO nanoparti- cles}

The animal experiments were performed according to the guidelines for the care and use of laboratory animals approved by Research Ethical Committee (Faculty of Science, Tanta University, Egypt), which is also in agreement with the guidelines of the National Institutes of Health (NIH). Number of ethical committee is (Rec-Sci-Tu-0317). Ehrlich Ascites Carcinoma (EAC) bearing donor mouse was provided by the $\mathrm{Na}$ tional Cancer Institute (Cairo University, Egypt). The tumor line was propagated in female mice in the ascetic form by sequential passages.

\section{Experimental Design}

Sixty adult female Swiss albino mice weighing 18 - 30 g, purchased from the breeding unit of Egyptian Organization for Biological Products and Vaccines (Abbassia, Cairo), were used throughout this work and provided with standard diet and tap water ad libitum. They were divided into six groups $(n=10)$. The G1, control group were injected in day " 0 ", then day other day with $0.1 \mathrm{ml}$ of isotonic saline; G2, ZnONPs group were injected day other day with ZnONPs in a dose of $20 \mathrm{mg} / \mathrm{Kg}$ body weight ${ }^{17}$; G3, EAC group were injected once with $0.1 \mathrm{ml}$ of $1 \times 10^{6}$ EAC cells/mouse in day "0", then with saline day other day ${ }^{18}$; G4, EAC mice injected day other day with doxorubicin in a dose of $2 \mathrm{mg} / \mathrm{Kg}$ body weight ${ }^{19}$; G5, EAC mice injected day other day with ZnONPs in a dose of $20 \mathrm{mg} /$ Kg body weight; G6, EAC mice injected day other day with a combination of doxorubicin $(2 \mathrm{mg} / \mathrm{Kg}$ body weight) and $\mathrm{ZnONPs}$ ( $20 \mathrm{mg} / \mathrm{Kg}$ body weight). All treatments were performed using intraperitoneal injection for 2 weeks. Treatment with doxorubicin and ZnONPs were begun after 24 hours of tumor induction.

On the $14^{\text {th }}$ day of the experiment, the animals were subjected to light anesthesia with ether, and the blood samples were collected and left to clot at room temperature, then centrifuged at $3000 \mathrm{rpm}$ for $10 \mathrm{mins}$. The supernatant was withdrawn and stored at $20{ }^{\circ} \mathrm{C}$ for further serum parameters. After blood withdrawal, the animals were sacrificed, and the ascetic fluid was withdrawn from the peritoneal cavity and the viability of cells was checked by $0.4 \%$ trypan blue. The livers and kidneys were excised, washed in isotonic saline, then divided into two parts. The first part was fixed in $10 \%$ neutral formalin and kept for histopathological examination. The second part was homogenized and kept at $-20{ }^{0} \mathrm{C}$ for further biochemical parameters.

\section{Serum and Tissue Biochemical Analysis}

Diagnostic kits for measuring serum ALT, AST, albumin, urea, and creatinine were purchased from a biodiagnostic company in Giza, Egypt. ALT, AST, albumin, and urea were estimated according to ${ }^{20}$, while creatinine was determined according to ${ }^{21}$.

The extent of lipid peroxidation in tissue homogenate was estimated by measuring the production of malondialdehyde (MDA) as an indicator of oxidative stress. MDA was determined by incubating the samples with $0.67 \%$ thiobarbituric acid and measuring the pinkcolored complex product TBARS at $532 \mathrm{~nm}^{22}$. The results were expressed as n moles of $\mathrm{MDA} / \mathrm{g}$ tissue using the extinction coefficient $(\varepsilon)$ equal to $156000 \mathrm{M}^{-1}$ $\mathrm{cm}^{-1}$. Reduced glutathione was determined according to the method of Beutler ${ }^{23}$, which is based on the reduction of 5, 5'-dithiobis-2-nitrobenzoic acid (DTNB) by reduced glutathione to give a yellowcolored TNB chromophore, and its absorbance can be measured at $412 \mathrm{~nm}$.

In addition, the antioxidant enzymes including catalase was assessed by monitoring the decomposition of $\mathrm{H}_{2} \mathrm{O}_{2}$ at $240 \mathrm{~nm}$ as described by Beers ${ }^{24}$. Concisely, 3 mL buffered $\mathrm{H}_{2} \mathrm{O}_{2}$ were pipetted in $3.0 \mathrm{~cm}$ quartz cuvette and $10 \mu \mathrm{L}$ of sample was added, then mixed by inversion. The absorbance was measured at zero time and after one minute at $240 \mathrm{~nm}$. One unit of enzyme activity was defined as the amount of enzyme that catalyzed the decomposition of $1 \mu \mathrm{mol} \mathrm{H}_{2} \mathrm{O}_{2} /$ min under assay condition by using an extinction coefficient of $0.0394 \mathrm{~mm}^{-1} \mathrm{~cm}^{-1}$.

Glutathione peroxidase (GPx) activity was measured based on the method of Rotruck ${ }^{25}$, which depends on the reaction between the remaining glutathione after the action of Gpx and Elmann's reagent (DTNB) to give yellow colored complex which absorbed at 412 $\mathrm{nm}$. One unit of enzyme activity was defined as the amount of enzyme that catalyzed the consumption of $1 \mu \mathrm{mol} \mathrm{GSH}$ per min. 
Glutathione S-transferase (GST) activity was estimated by measuring the absorbance of dinitrophenyl thioether adduct formed due to conjugation between GSH and 1-chloro-2, 4 dinitrobenzene (CDNB) at 340 $\mathrm{nm}^{26}$. One unit of enzyme activity was defined as the amount of enzyme producing 1 nmol of product per min using an extinction coefficient of $9.6 \mathrm{mM}^{-1}$ $\mathrm{cm}^{-1}$.

\section{Cell Cycle Analysis by Flow Cytometry}

The analysis of DNA content by flow cytometry was conducted according to the method of ${ }^{27}$ to support the cytotoxicity of ZnONPs towards EAC cells. In brief, EAC cells were washed twice with PBS and centrifuged. The supernatant was discarded and the cells were fixed in $500 \mu \mathrm{L}$ of $70 \%$ ice-cold ethanol for at least 2 hours at $-20{ }^{\circ} \mathrm{C}$. The mixture was centrifuged at $1000 \mathrm{rpm}$ for $5 \mathrm{mins}$ to remove the ethanol. The fixed cells were washed with PBS and mixed with 500 $\mu \mathrm{L}$ of PI (propidium iodide) staining solution. Before analysis, the stained cells were incubated in darkness for $30-60$ mins at room temperature. Then the samples were analyzed using Accuri C6 Flow Cytometer (Becton Dickinson, Sunnyvale, CA, USA).

\section{Western Blot Analysis}

Immunoblotting was conducted following the method reported by ${ }^{28}$. Briefly, the total cell proteins were isolated by RIPA lysis buffer and the concentration total protein concentration was measured by Bradford assay ${ }^{29}$. Equal amounts of protein $(20 \mu \mathrm{g})$ were separated on $12 \%$ SDS-PAGE and transferred to polyvinylidene difluoride (PVDF) membranes. The membranes were blocked with $5 \%$ non-fat dry milk, then incubated with anti-Bcl 2 (Abcam, AB59348), anti-Bax (Abcam, AB3191) and anti-Caspase3 (Abcam, AB184787) (1:1000) overnight at $4{ }^{\circ} \mathrm{C}$. After washing, the membranes were incubated with an HRP secondary antibody (Abcam, AB97051) for 1 hour, then the chemiluminescent ECL substrate (PerkinElmer, USA, NEL103E001EA) was applied to the plot to detect the protein bands. Finally, these bands were analyzed by using image J software, and $\beta$-actin (Abcam, AB8226) was used as internal control $^{30}$.

\section{Histopathological Studies}

Small pieces of liver and kidney tissues which isolated from different experimental groups were fixed in $10 \%$ formalin and then dehydrated using different concentrations of alcohol. The dehydrated tissues were embedded into paraffin, sectioned for $4 \mathrm{~mm}$ thick and mounted on the glass slides. The tissue sections were stained by hematoxylin and eosin and examined by light microscope ${ }^{31}$.

\section{Statistical Analysis}

All data were expressed as mean $\pm \mathrm{SD}$ of three replicates from each experimental group. For comparison between groups, the data were analyzed by oneway of variance (ANOVA), followed by Tukey's test in GraphPad Prism Software 6 (San Diego, CA). Probability values of less than $0.05(P<0.05)$ were considered to be statistically significant.

\section{RESULTS}

\section{Characterization Results of the Green Syn- thesized ZnO}

Zinc oxide nanoparticles were prepared by using fenugreek seeds aqueous extract that formed a cloudy solution when added to a colorless solution of zinc nitrate. $6 \mathrm{H} 2 \mathrm{O}$, then turned into a yellowish white precipitate after adding sodium hydroxide. The SEM image of the prepared ZnONPs demonstrated a 3D hierarchical flower-like nanostructure with an average diameter of $1.7 \mu \mathrm{m}$ (Figure 1I). The elemental composition of the prepared sample was analyzed by Energy-dispersive X-ray. The spectrum in Figure $1 \mathrm{II}$ revealed that the $3 \mathrm{D}$ flower-like nanostructure of $\mathrm{ZnO}$ contains three elements, namely zinc, oxygen and carbon, the atomic percentages of these elements being $20.59 \%, 45.01 \%$ and $34.40 \%$ respectively. Further, the XRD pattern of the green synthesized $\mathrm{ZnONPs}$ revealed various peaks at $2 \theta$ values of $31.92^{\circ}, 34.42^{\circ}, 36.31^{\circ}, 47.52^{\circ}, 56.68^{\circ}, 62.93^{\circ}$ and $67.98^{\circ}$ which corresponded to (100), (002), (101), (102), (110), (103) and (112) crystal planes respectively (Figure 1III). The average crystalline size of ZnONPs, derived from the FWHM of a more intense peak corresponding to the (101) plane (located at $36.31^{\circ}$ ) was estimated to be $15.41 \mathrm{~nm}$ using Scherrer's formula. FTIR (Figure 1IVA) was recorded to identify the most important functional groups on the fenugreek extract to examine their role in the manufacture and capping of $\mathrm{ZnO} 3 \mathrm{D}$ flower-like structure. The spectrum showed a high absorption peak of $3446 \mathrm{~cm}^{-1}$ and a strong band at a frequency of 1657 $\mathrm{cm}^{-1}$. In addition to that, another small band appeared at $1446 \mathrm{~cm}^{-1}$. For $\mathrm{ZnO}$, a broad band appeared at $420 \mathrm{~cm}^{-1}$ beside the main bands existing in the extract with a slight shift (Figure 1IVB). UVVis spectroscopy is an effective method in the affirmation of nanostructures' optical properties. UVVis spectroscopy initially confirmed the formation of 


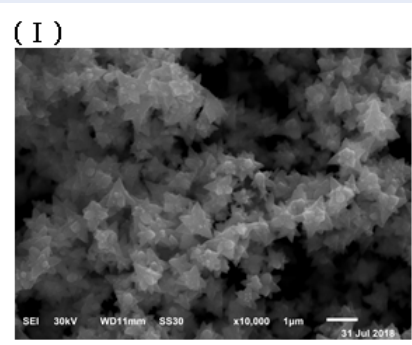

$(\mathrm{N})$

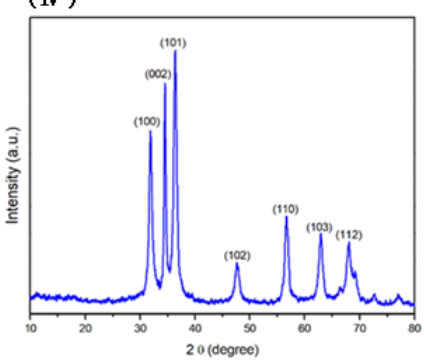

( II )

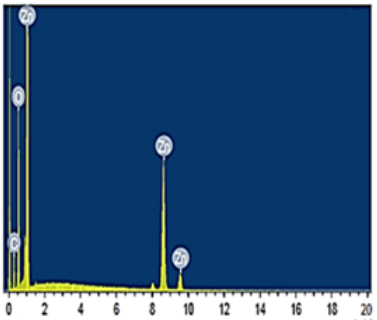

(V)

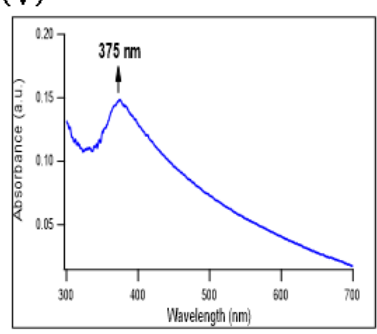

(III)

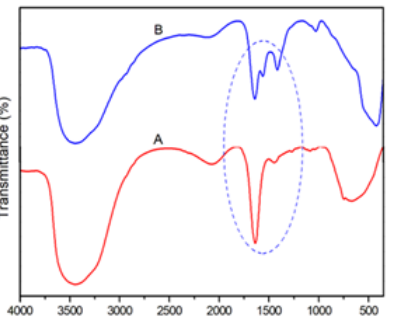

(V) Wavenumber (om')

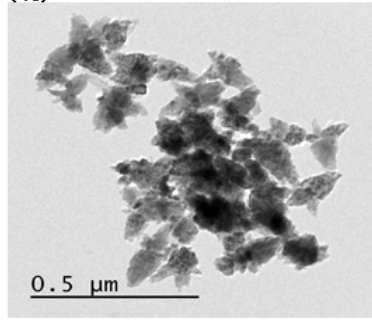

Figure 1: Characterization of 3D flower-like nanostructure of $\mathrm{ZnO}$, synthesized at room temperature using fenugreek seeds aqueous extract (5\%). (I): SEM image, (II): EDX spectrum, (III): X-ray diffraction pattern, (IV): FTIR spectra of fenugreek seeds aqueous extract (A) and the 3D flower-like nanostructure of ZnO (B), (V): UV-vis spectrum and (VI): TEM image.

https://doi.org/10.6084/m9.figshare.16529037.v1
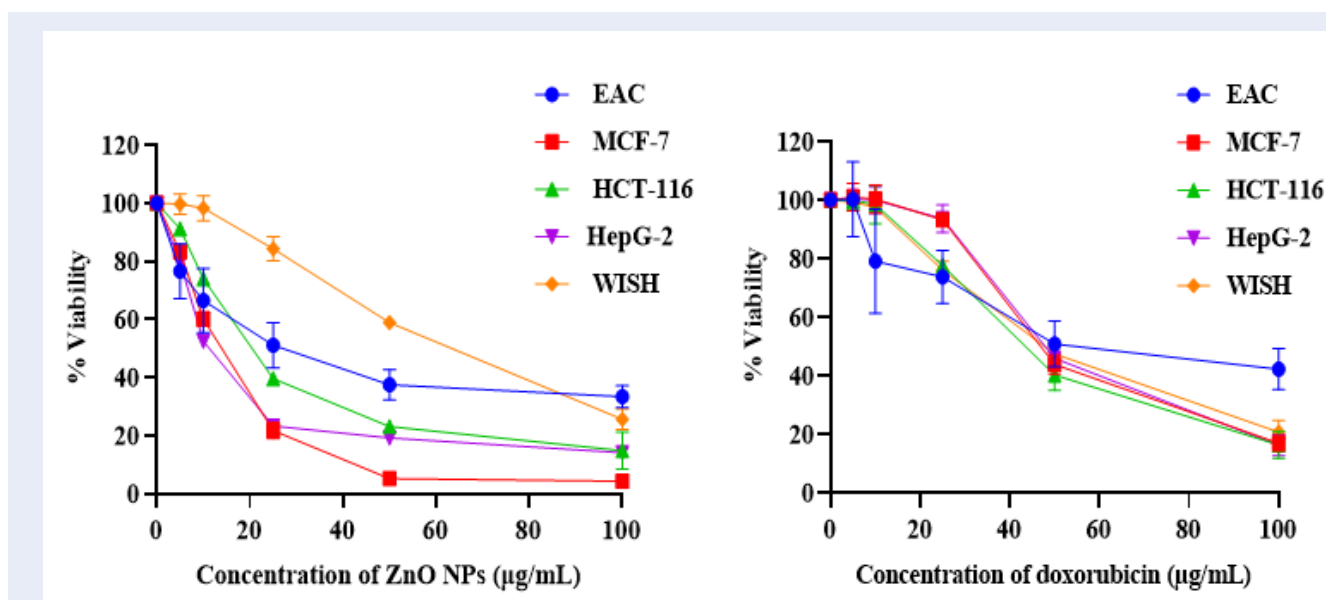

Figure 2: Effect of ZnONPs and doxorubicin on the viability of different cancer cell lines. Cells treated with different concentrations of ZnONPs and doxorubicin for $48 \mathrm{hr}$ then cell viability was determined by MTT assay and $\mathrm{IC}_{50}$ was calculated. Results are expressed as Mean $\pm \mathrm{SD}$ of three experiments performed in triplicates. https://doi.org/10.6084/m9.figshare.16529040.v1 
(A)

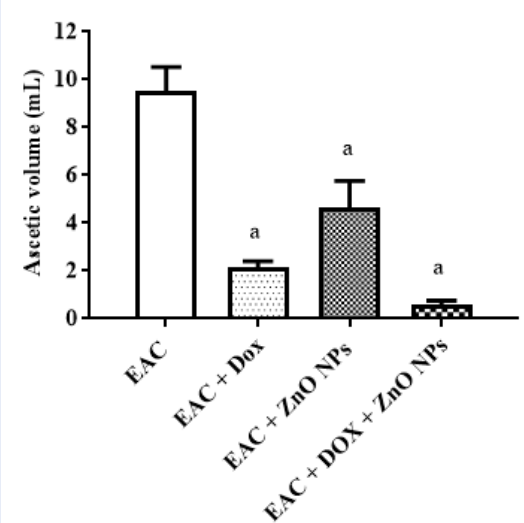

(B)

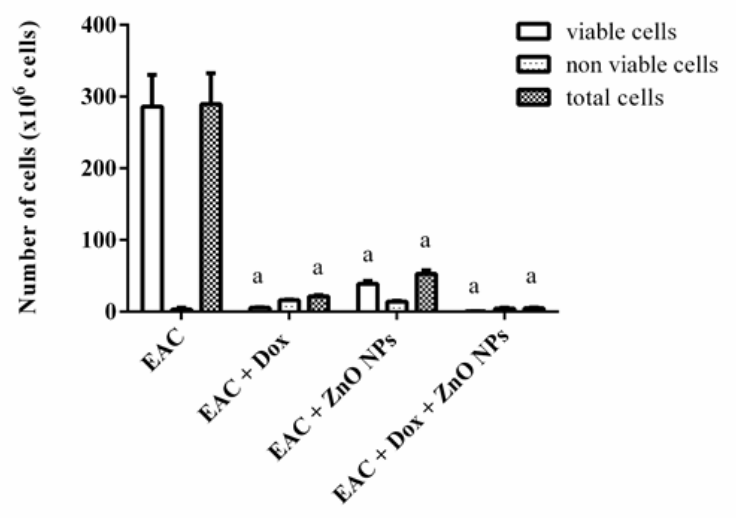

Figure 3: Effect of ZnONPs on the ascetic volume (A) and EAC tumor cell count (B) in EAC treated groups. Tumor-bearing mice administrated ZnONPs $(20 \mathrm{mg} / \mathrm{kg}$, i.p, day other day) and / or doxorubicin $(2 \mathrm{mg} / \mathrm{kg}$, i.p, day other day). Results are expressed as mean \pm SD. $\mathrm{P}<0.05$ is statistically considered significant, where a: significant difference compared to EAC group.

https://doi.org/10.6084/m9.figshare.16529043.v1

ZnONPs within a range of $300-600 \mathrm{~nm}$. The absorption spectrum of the 3D flower-like nanostructure of $\mathrm{ZnO}$ showed a distinctive band at $375 \mathrm{~nm}$ (Figure 1V). TEM of the green synthesized ZnONPs was conducted to further investigate the topography structure of the prepared nanoparticles. TEM image (Figure 1VI) revealed a flower-like shape which is in good agreement with the findings of SEM. Moreover, these images show $\mathrm{ZnO}$ nanospheres with variable diameters, which were assembled into nanorods. Such nanorods were self-assembled to the 3D hierarchical flower-like s tructure. In a ddition to that, the polydispersity index and zeta potential of the prepared ZnONPs was studied using dynamic light scattering measurements as shown in Fig. S1 and S2 (supplementary data) respectively.

\section{In Vitro Antitumor Activity of the 3D Flower-like Nanostructure of ZnO}

The cytotoxicity of ZnONPs was investigated by MTT assay using diverse cancer cell lines and doxorubicin as a chemotherapeutic guide drug. The data represented in Figure 2 showed an inverse relation between $\mathrm{ZnONPs}$ concentration and the viability of cancer cells, and the inhibitory concentration was found to be 27.09, 12.35, 20.7 and $12.05 \mu \mathrm{g} / \mathrm{mL}$ for EAC, MCF-7, HCT-116 and HepG-2 cells respectively. In contrast, the results revealed that there is a non-significant effect on normal cells (WISH) upon ZnONPs exposure up to $30 \mu \mathrm{g} / \mathrm{mL}$. On the other hand, doxorubicin showed a cytotoxic effect on both cancer and normal cells.

In vivo Antitumor Activity of the 3D Flowerlike Nanostructure of $\mathrm{ZnO}$ against Ehrlich Ascites Carcinoma

To study the antitumor effect of ZnONPs against EAC mice model in vivo, the change in the body weight, ascetic volume and total tumor cell count in different experimental groups were measured. The results in Table 1 showed a significant increase $(P<0.0001)$ in the body weight of EAC mice (G3) by $24.3 \%$ compared to control mice (G1). In addition, treatment of tumor-bearing mice with $\mathrm{ZnONPs}$ and/or doxorubicin (DOX) revealed a remarkable decrease in their body weight by $15.5,19.9$ and $25.5 \%$ respectively compared to the untreated EAC group. Moreover, ZnONPs (G5), doxorubicin (G4) or combined treated (G6) groups displayed a significant decrease not only $(\mathrm{P}<0.0001)$ in the ascetic volume (Figure 3A), but also in the total and viable tumor cell count in comparison with untreated EAC mice (Figure 3B).

\section{Effect of ZnONPs on Serum and Tissue Bio- chemical Assessment}

In this study, serum ALT and AST activities as well as urea and creatinine concentrations showed a significant increase $(\mathrm{P}<0.0001)$ in EAC (G3) and doxorubicin treated mice (G4) in comparison with the control group (G1). The administration of ZnONPs in 
(A)

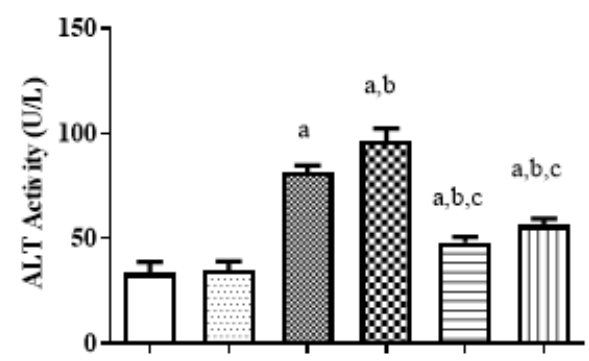

(B)

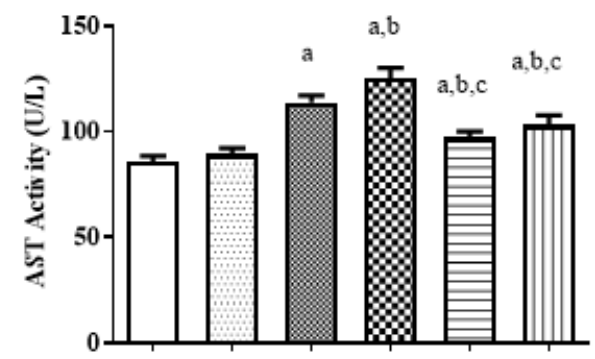

(D)

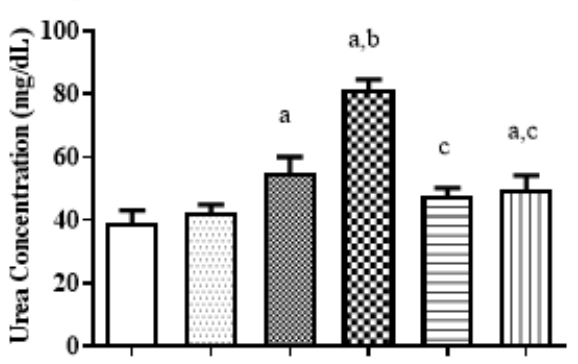

D Control

ZnO NPs

EAC

EAC + DOX

口 $\mathrm{EAC}+\mathrm{ZnO} \mathrm{NPs}$

EAC + DOX + ZnO NPs
(C)

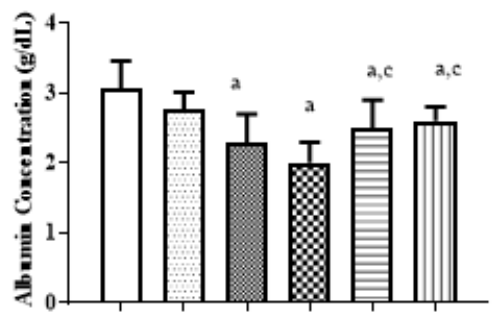

(E)

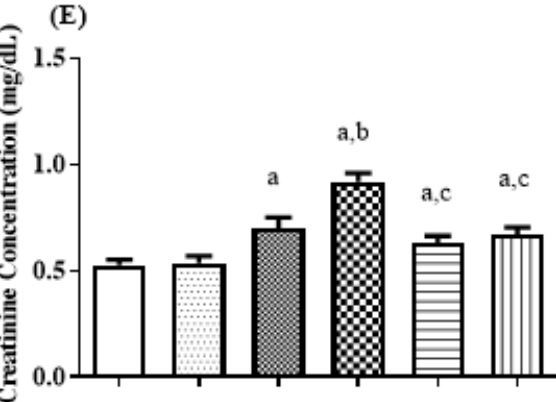

Figure 4: A graphical presentation of liver and kidney functions in different experimental g roups. A: ALT (alanine aminotransferase) activity, B: AST (aspartate aminotransferase) activity, C: albumin level, D: urea concentration, and $\mathbf{E}$ : creatinine concentration. Results are expressed as mean \pm SD. $\mathrm{P}<0.05$ is statistically considered significant, where a: significantly different from control group, b: significantly different from EAC group and $\mathbf{c}$ : significantly different from doxorubicin group.

https://doi.org/10.6084/m9.figshare.16529046.v1

tumor bearing mice remarkably decreases their levels. On the other hand, the level of albumin in EAC mice and doxorubicin treated groups revealed a notable decrease $(P<0.0001)$ relative to the control group. Furthermore, the administration of $\mathrm{ZnONPs}$ alone or combined with doxorubicin upgraded the level of albumin (Figure 4).

In addition, the level of MDA was significantly increased, coupled with significant suppression in the level of GSH in EAC (G3) and doxorubicin treated mice (G4) compared with control group (G1) as indicated in Figure 5A, B. All groups treated with ZnONPs alone (G5) or in combination with doxorubicin (G6) significantly corrected the levels of MDA and GSH. Moreover, the activity of antioxidant enzymes Gpx, GST and catalase showed a significant decrease $(P<0.0001)$ in tumor-bearing mice $(G 3)$ and doxorubicin treated group (G4) in comparison with control one (G1). On the other hand, the administration of ZnONPs led to a remarkable increase $(\mathrm{P}<$ 0.0001 ) in the activities of these antioxidant enzymes as compared to EAC (G3) and doxorubicin treated groups (Figure $5 \mathrm{C}, \mathrm{D}, \mathrm{E}$ ). 
(A)

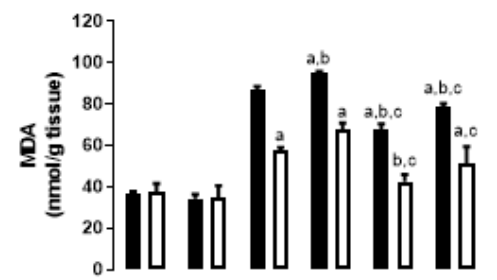

(B)

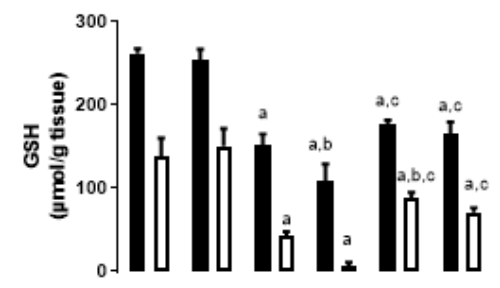

(D)

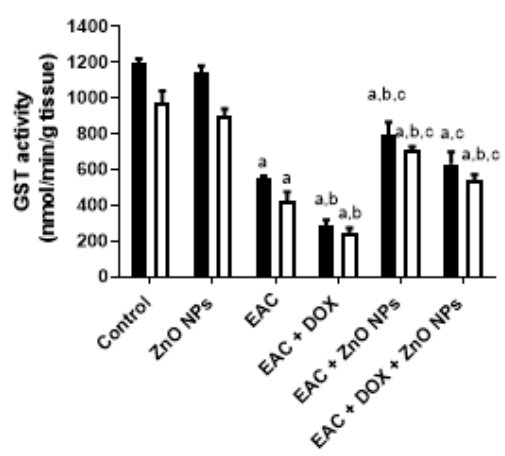

- Hepatic

口 Renal
(C)

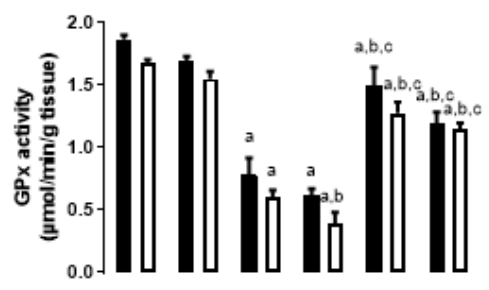

(E)

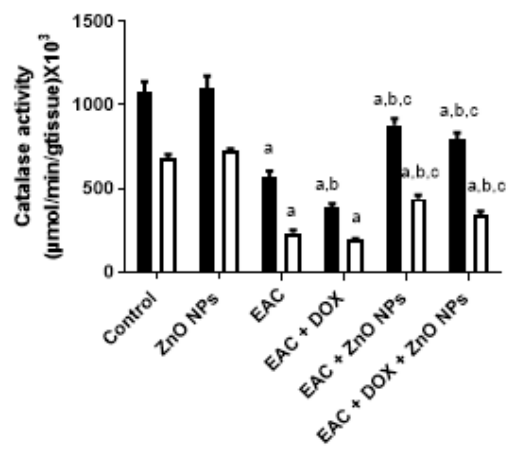

Figure 5: A graphical presentation of hepatic and renaloxidative stress markers in different experimental groups. A: MDA (malondialdehyde) level, B: GSH (reduced glutathione) level, C: Gpx (glutathioneperoxidase) activity, D: GST (glutathione $s$ transferase) activity and E: catalase activity. Results are expressed as mean $\pm \mathrm{SD}$. $\mathrm{P}<0.05$ is statistically considered significant, $\mathrm{w}$ here a : $\mathrm{s}$ ignificantly di fferent fro $\mathrm{m}$ control group, b: significantly different from EAC group and c: significantly different from EAC+ DOX group. https://doi.org/10.6084/m9.figshare.16529055.v1

Effect of the 3D Flower-like Nanostructure of $\mathrm{ZnO}$ and/or Doxorubicin on Cell Cycle Distribution

The results obtained through the single treatment of EAC mice with doxorubicin (G4) or with $\mathrm{ZnO}$ NPs (G5) showed arresting of the cell cycle at G0/G1 phase by significantly increasing $(\mathrm{P}<0.01)$ the number of cell populations to 68 and $61 \%$ respectively compared to EAC group (G3). In addition, the coadministration of DOX and ZnONPs in mice injected with tumor cells led to a massive increase $(\mathrm{P}<0.001)$ of cells with G0/G1 DNA content by $73.15 \%$. On the other hand, a sensible decrease $(\mathrm{P}<0.05, \mathrm{P}<0.01)$ in S-phase was observed in all EAC treated groups. Moreover, the proportion of cells in G2/M phase was less affected compared to G0/G1 phase (Figure 6).

Apoptotic Induction by the 3D Flower-like Nanostructure of $\mathrm{ZnO}$ and/or Doxorubicin in EAC

To determine the extent of ZnONPs and/or doxorubicin on apoptosis regulating proteins, the expression levels of caspase-3, BAX and Bcl-2 were investigated by western blot analysis. As shown in Figure 7, all EAC treated groups showed an upregulation in the expression level of caspase- 3 and Bax. In contrast, 
EAC

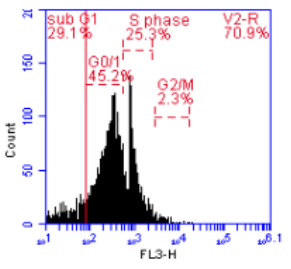

$E A C+Z n O N P s$

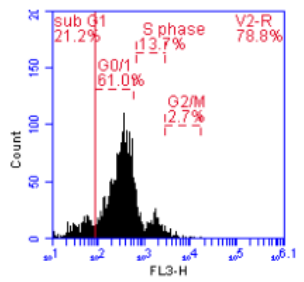

$E A C+D O X$

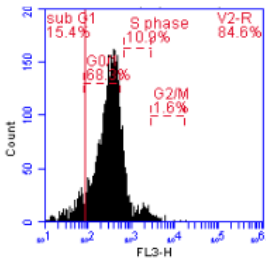

$E A C+D O X+Z n O N P s$

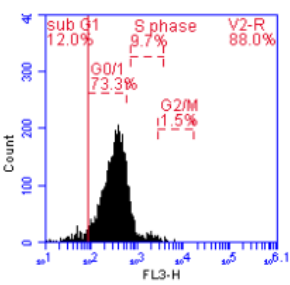

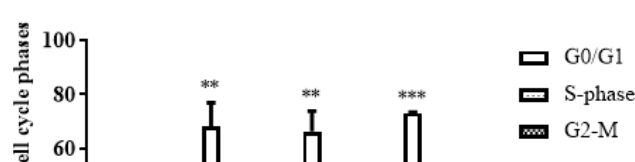

Figure 6: Cell cycle analysis of EAC treated with ZnO 3D flower-like nanostructure and/or doxorubicin afte staining with PI. The tumor-bearing mice are treated with ZnO (20 mg/kg, i.p, day other day) and/ or doxorubicin ( $2 \mathrm{mg} / \mathrm{kg}$, i.p, day other day) for two weeks. Results are expressed as mean \pm SD. $\mathrm{P}<0.05$ is statistically considered significant, where *: significantly different from EAC group.

https://doi.org/10.6084/m9.figshare.16529061.v1

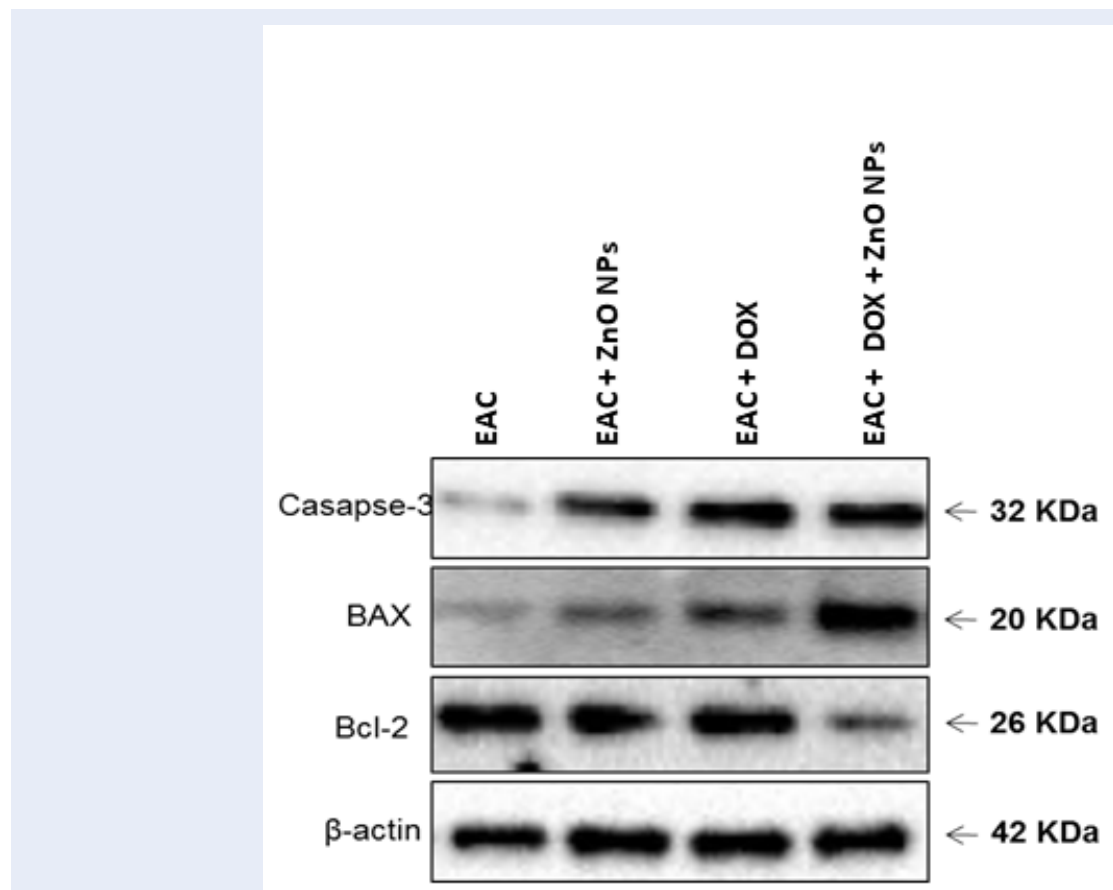

Figure 7: Protein expression of caspase 3, Bax and $\mathrm{BCl}_{2}$ in EAC treated with ZnONPs, doxorubicin alone or in combination observed by Western blotting assay.

https://doi.org/10.6084/m9.figshare.16529067.v 


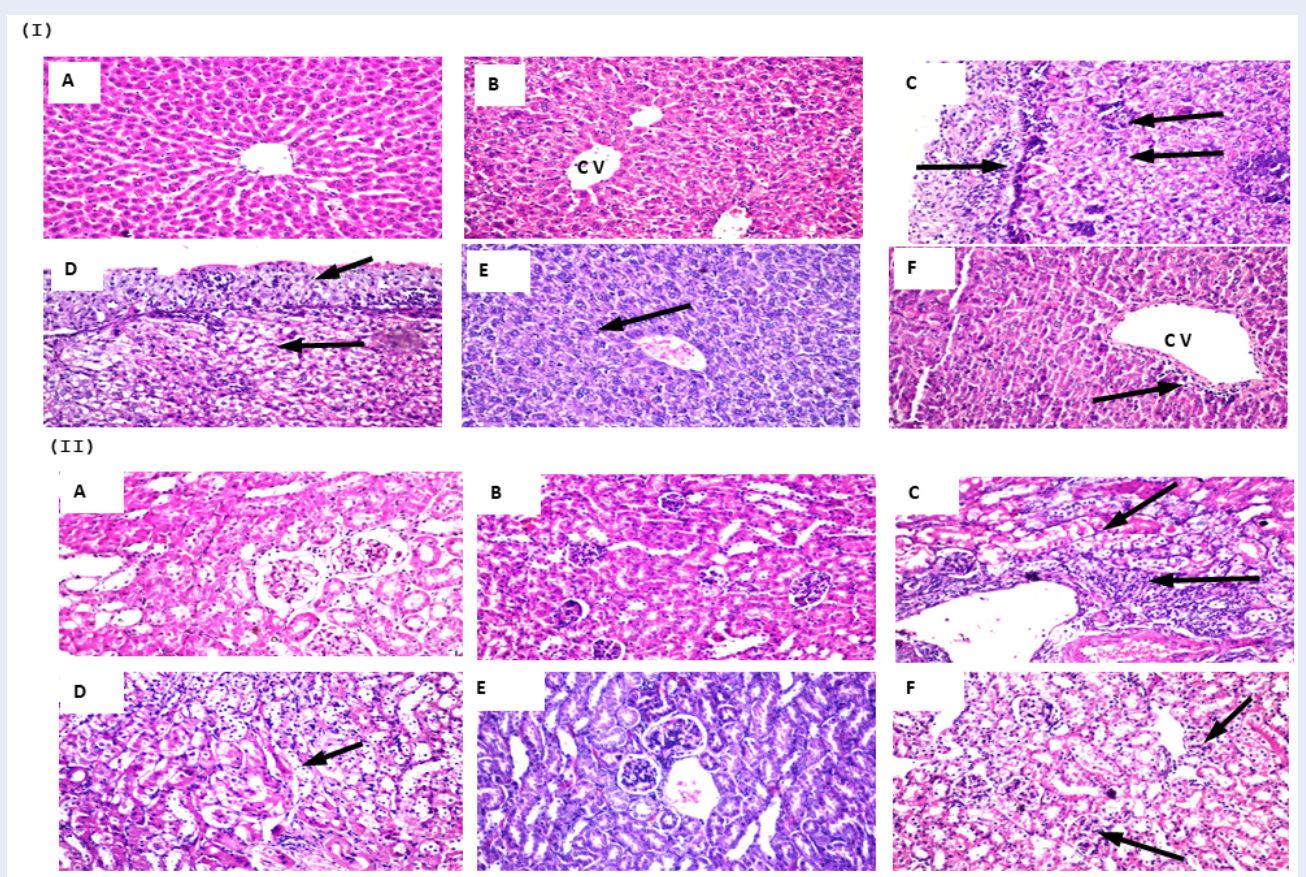

Figure 8: Photomicrographs representing histochemistry of liver (I) and kidney (II) sections stained with H\&E in different experimental groups. A: control; B: ZnO NPs; C: EAC; D: EAC + DOX; E: EAC + ZnONPs; F: EAC + DOX + ZnONPs.

https://doi.org/10.6084/m9.figshare.16529070.v1

Table 1: The table below shows the body weight of the mice at the start and the sacrifice in different experimental groups

\begin{tabular}{lccc}
\hline Groups & Body weight at start (g) & Body weight at sacrifice (g) & $\begin{array}{c}\text { \% of body weight } \\
\text { change }\end{array}$ \\
\hline Control & $20.6 \pm 6.0$ & $21.56 \pm 4.4$ & 4.6 \\
ZnONPs & $21 \pm 2.5$ & $22.2 \pm 0.5$ & 24.36 \\
EAC & $21.68 \pm 2.0$ & $28.6 \pm 3.1^{a}$ & 2.5 \\
EAC + DOX & $22.36 \pm 1.6$ & $22.9 \pm 0.7^{b}$ & 7.04 \\
EAC + ZnONPs & $22.56 \pm 2.2$ & $24.15 \pm 0.8^{b}$ & 2.03 \\
EAC + DOX + ZnONPs & $20.9 \pm 1.7$ & $21.3 \pm 1.0^{b}$ & \\
\hline
\end{tabular}

Mice were treated 24 hours after inoculation of EAC $\left(1 \times 10^{6}\right.$ cells $)$ with ZnONPs $(20 \mathrm{mg} / \mathrm{kg}$, i.p, day other day $)$ and doxorubicin $(2 \mathrm{mg} / \mathrm{kg}$, i.p day other day) for 2 weeks. Results are expressed as mean $\pm \mathrm{SD}$. ${ }^{\mathbf{a}} \mathrm{P}$ significant difference compared to control group, ${ }^{\mathbf{b}} \mathrm{P}$ significant difference compared to EAC group. 
the expression of the antiapoptotic $\mathrm{Bcl}-2$ protein was downregulated in all treated groups, and the combinational treatment showed a superior reduction.

\section{Histological Analysis}

Histological examination of tissues from control mice (G1) and ZnONPs group (G2) showed normal histological structure of the central vein and surrounding hepatocytes in the liver and normal renal tubular and glomerular structures in the kidney (Figure 8IA, B and IIA, B). In EAC mice (G3), histological assessment of liver and kidney tissues showed massive inflammatory cell infiltration, degeneration and necrosis in the hepatocytes and renal tubules (Figure 8IC and IIC). Doxorubicin treated mice (G4) displayed congestion in the portal vein with degeneration in the surrounding hepatocytes in liver histopathology, and congestion in the cortical blood vessels associated with degenerative and necrobiotic changes in the lining epithelium of the renal tubules in kidney histopathology (Figure 8ID and IID). Besides, histological examination of liver and kidney tissues in EAC mice treated with ZnONPs alone (G5) or in combination with doxorubicin (G6) showed few inflammatory cells in the hepatocytes and minimal degeneration in the lining epithelium of the renal tubules (Figure 8 IE, F and IIE, F).

\section{DISCUSSION}

Cancer is still the second leading cause of death worldwide despite advances in its diagnosis and treatment. Recently, different nanoparticles were used in vitro and in vivo research to improve the diagnosis and treatment of cancer. Zinc oxide nanoparticle is one of the most important nanoparticles applied for cancer treatment due to its biocompatibility, easy synthesis, enhanced cytotoxicity and selectivity ${ }^{32}$. However, the cytotoxicity of some nanoparticles synthesized by chemical methods has been confirmed on normal cells even at lower concentrations. Over the last few years, the green synthesis of zinc oxide nanoparticles attracted the interest of researchers as an alternative method for nanoparticles preparation due to its low biotoxicity $^{33}$. The synthesis of nanoparticles using plant extractions has more advantages over the other biological methods because it doesn't need any special conditions and is inexpensive.

In this study, through the green synthesis method, ZnO's 3D hierarchical flower-like nanostructure was prepared using a fenugreek seed aqueous extract. Diverse characterization techniques have been used to analyze the properties of $\mathrm{ZnO}$ such as XRD, SEM, UVVis, FTIR, and EDX. We have investigated the morphological structure of the biosynthesized $\mathrm{ZnO}$ using SEM and TEM, and indicated that $\mathrm{ZnO}$ exhibited a 3D hierarchical flower-like structure. This structure was first recorded through the process of green synthesis. In addition, the presence of carbon peak in EDX spectra might indicate that the biomolecules present in the extract are responsible for the bio reduction and stabilization of ZnONPs. FTIR was conducted to determine the biomolecules in fenugreek seed extract, which play an important role in the reduction and stabilization processes of the formed ZnO. The FTIR spectrum showed a high absorption peak of $3446 \mathrm{~cm}^{-1}$ due to the stretching vibration of the O-H group in polyphenols or $\mathrm{N}-\mathrm{H}$ groups of proteins ${ }^{34}$. The strong band at a frequency of 1657 $\mathrm{cm}^{-1}$ due to $(\mathrm{C}=\mathrm{O}$, amide $\mathrm{I})$ are characteristics of proteins/enzymes, other small bands at $1446 \mathrm{~cm}^{-1}$ for $\mathrm{C}-\mathrm{O}$ stretching vibrations of polysaccharide and polyphenols. Moreover, there was a sharp band at 420 $\mathrm{cm}^{-1}$ due to the vibration mode of $\mathrm{Zn}-\mathrm{O}$ bond. This strongly supports that the extract acts not only as a reductant but also as a stabilizer and capping agent for the synthesized $3 \mathrm{D}$ flower-like nanostructure of $\mathrm{ZnO}$. Other studies suggested that the compounds present in brown algae extract could serve as capping agents to prevent ZnONPs' aggregation ${ }^{25}$. Also, the EDX spectrum of $3 \mathrm{D}$ hierarchical $\mathrm{ZnO}$ revealed the presence of three peaks for zinc, oxygen and carbon. Such carbons are supposed to be from the biomolecules in fenugreek extract which act as capping agents during the synthesis process. XRD pattern confirmed the standard hexagonal wurtzite structure (JCPDS, 361451) of the synthesized $\mathrm{ZnO}$. In line with a previous study, this would support the creation of a $3 \mathrm{D}$ hierarchical-flower-like nanostructure of $\mathrm{ZnO}^{35}$.

The in vitro cytotoxicity results suggest a promising anticancer potential for the 3D flower-like nanostructure of $\mathrm{ZnO}$ with inhibitory concentration varying from one cancer cell line to another in addition to lower cytotoxicity against normal cells. On the other hand, commercial chemotherapy (DOX) exhibited the same cytotoxic effect on cancer and normal cells. This inability of doxorubicin to differentiate between cancer and normal cells is one of the greatest challenges that cancer chemotherapy is facing at this time. The 3D flower-like nanostructure of $\mathrm{ZnO}$ has selective killing properties which may be due to the generation of reactive oxygen species ${ }^{36}$. This finding is broadly in agreement with earlier studies ${ }^{3}$, which found that $\mathrm{ZnONPs}$ prepared by using aqueous extract of Deverra tortuosa showed a selective cytotoxic 
effect on Caco-2 and A549 cancer cells with lower cytotoxicity on normal W138 cells. Another study revealed that $\mathrm{IC}_{50}$ value for purchased $\mathrm{ZnONPs}$ with an average particle size of $35 \mathrm{~nm}$ on HEPG2, PC3 and A549 tumor cell lines were 34.67, 36.31 and 21.38 $\mu \mathrm{g} / \mathrm{mL}$ respectively ${ }^{37}$.

The anticancer activity of the biologically synthesized ZnONPs in vivo was investigated by using the EAC model. Our results showed that $\mathrm{ZnO}$ inhibits the proliferation and growth of EAC by decreasing the body weight, ascetic volume and viable tumor cell count either alone (G5) or in combination with doxorubicin (G6) compared to untreated EAC mice (G3). These results come in full agreement with previous studies $^{38}$, which observed that the oral administration of ZnONPs at doses of 300 and $500 \mathrm{mg} / \mathrm{kg}$ inhibited the rate of tumor growth by 31.5 and $46 \%$ respectively in Ehrlich solid carcinoma (ESC) bearing mice compared to the untreated group. Moreover, our study indicated that the administration of ZnONPs ameliorates the toxicity caused by doxorubicin as well as enhances the antioxidant defense system in the liver and kidney tissues of the treated groups. Intraperitoneal injection of $20 \mathrm{mg} / \mathrm{kg} \mathrm{ZnONPs} \mathrm{exerted} \mathrm{a} \mathrm{signif-}$ icant decrease in the liver and kidney functions that elevated due to tumor inoculation and doxorubicin administration. This finding is supported by Nabeel, who demonstrated that treatment with ZnONPs decreased liver function enzymes near the normal control; the decrement was significant to the untreated Ehrlich carcinoma (EC) solid tumor group ${ }^{39}$. Furthermore, the activity of antioxidant enzymes is increased and coupled with a remarkable decrease in the oxidative stress marker (MDA) level in ZnONPs treated groups. Our findings are in harmony with previous studies by Hassan et al., who reported that ZnONPs has a good antioxidant effect mediated by elevation in antioxidant enzymes GST, Gpx, SOD and GR, coupled with suppression of MDA level in hepatocellular carcinoma(HCC) rats treated with $\mathrm{ZnONPs}$ compared with rats administrated DENA without treatment ${ }^{37}$.

One strategy in the discovery and progression of new anticancer drugs is the regulation of the cancer cell cycle $^{40}$. So in this study, the effect of the biologically synthesized ZnONPs on different cell cycle phases and distribution was conducted to clarify its cytotoxicity and antiproliferative activity mechanism towards EAC. Cell cycle analysis results showed that the tumor-bearing mice treated with single therapy of doxorubicin or ZnONPs could block the cell cycle by increasing the number of cell populations with
G0/G1 DNA content. This increment was more evident in EAC received combinations of doxorubicin and ZnONPs. These observations indicated that the cell cycle arrest is an important step in the apoptotic pathway. This apoptotic induction was confirmed through the upregulation of pro-apoptotic Bax and caspase- 3 and the downregulation of anti-apoptotic $\mathrm{Bcl}-2$ in the treated groups. Kavithaaet al. reported that $\mathrm{ZnO}$ nanorods induced apoptosis in MCF-7 cells after 48 hours of treatment via G0/G1 and S phase cell cycle arrest ${ }^{41}$. Consistent with our findings, Sharma et al., reported that HepG-2 cells exposed to ZnO NPs for 9 hours showed an increase in Bax levels and a corresponding decrease in $\mathrm{Bcl}-2^{42}$. Our results were also confirmed by another study of Bai et al., who showed that $\mathrm{ZnONPs}$ with an average size of $20 \mathrm{~nm}$ upregulated the level of Bax and caspase-9, and downregulated the level of $\mathrm{Bcl}-2$ protein in ovarian cancer cell line (SKOV-3) after 12 hours of $\mathrm{ZnO}$ exposure ${ }^{16}$. Furthermore, our result is in agreement with Abosharaf et al., who demonstrated that biogenic silver nanoparticles induce EAC apoptosis via upregulation of caspase 3 and Bax, and down-regulation of $\mathrm{Bcl}-2^{43}$.

Histopathological analysis of our study demonstrated that the biologically synthesized ZnONPs can regenerate the damage caused by the inoculation of tumor cells and the administration of doxorubicin in liver and kidney tissues. These results came in harmony with previous study which demonstrated that the intraperitoneal injection of ZnONPs in Ehrlich solid tumor mice regenerated the lesions occurred in liver tissue $^{17}$

\section{CONCLUSIONS}

This study presents a facile, cost-effective, healthy and eco- friendly route to fabricate the hierarchical 3D flower-like nanostructure of $\mathrm{ZnO}$ on a large scale for the first time through a green approach using aqueous extract of fenugreek seeds at room temperature. These biologically synthesized zinc oxide nanoparticles had a cytotoxic effect and antitumor activity against Ehrlich ascites carcinoma in vivo. This activity may be related to stimulation of cell cycle arrest at G0/G1 phase, upregulation of proapoptotic proteins and downregulation of antiapoptotic proteins. Collectively, our data suggested that the green synthesized 3D flower-like nanostructure of $\mathrm{ZnO}$ could be of great prominence in the medical field due to their anticancer activity.

\section{ABBREVIATIONS}

DOX: Doxorubicin

EAC: Ehrlich ascites carcinoma 
EDX: Energy dispersive X-ray

SEM: Scanning electron microscope

TEM: Transmission electron microscope

XRD: X-ray diffraction

ZnO NPs: Zinc oxide nanoparticles

\section{ACKNOWLEDGMENTS}

We would like to thank the central laboratory of Tanta University, Egypt where X-ray diffraction and FTIR were carried out. Special thanks to Dr/ Hamed Abosharaf, Biochemistry Division, Chemistry Department, Faculty of Science, Tanta University for his valuable help in the analysis of data.

\section{AUTHOR'S CONTRIBUTIONS}

Mai M. El-Keiy: Supervision, Editing. Aliaa M. Radwan: Methodology, Formal analysis, and Writing an original version of the manuscript. Eman F. Aboelfetoh: Analysis, Editing. Tetsunari Kimura: Supervision, Writing-review. Tarek M. Mohamed: Conceptualization, Supervision, Writing-editing. All authors read and approved the final manuscript.

\section{FUNDING}

None.

\section{AVAILABILITY OF DATA AND MATERIALS}

Not applicable.

\section{ETHICS APPROVAL AND CONSENT TO PARTICIPATE}

The experimental design was approved by Research Ethical Committee (Faculty of Science, Tanta University, Egypt) which is also in agreement with the guidelines of the National Institute of Health (NIH). Number of ethical committee is (Rec-Sci-Tu-0317).

\section{CONSENT FOR PUBLICATION}

Not applicable.

\section{COMPETING INTERESTS}

The authors declare that they have no competing interests.

\section{REFERENCES}

1. Banerjee HN, Verma M. Application of nanotechnology in cancer. Technol Cancer Res Treat. 2008;7(2):149-54. PMID 18345704. Available from: 10.1177/153303460800700208.

2. Gmeiner WH, Ghosh S. Nanotechnology for cancer treatment. Nanotechnol Rev. 2015;3(2):111-22. PMID: 26082884

3. Selim YA, Azb MA, Ragab I, El-Azim MHMA. Green synthesis of zinc oxide nanoparticles using aqueous extract of Deverra tortuosa and their cytotoxic activities. Sci Rep. 2020;10(1):3445.
PMID: 32103090. Available from: 10.1038/s41598-020-605411.

4. Aboelfetoh EF, Gemeay AH, El-Sharkawy RG. Effective disposal of methylene blue using green immobilized silver nanoparticles on graphene oxide and reduced graphene oxide sheets through one-pot synthesis. Environ Monit Assess. 2020;192(6):355. PMID: 32394116. Available from: 10.1007/ s10661-020-08278-2.

5. Aboelfetoh EF, El-Shenody RA, Ghobara MM. Eco-friendly synthesis of silver nanoparticles using green algae (Caulerpa serrulata): reaction optimization, catalytic and antibacterial activities. Environ Monit Assess. 2017;189(7):349. PMID: 28646435. Available from: 10.1007/s10661-017-6033-0.

6. Wani SA, Kumar P. Fenugreek: A review on its nutraceutical properties and utilization in various food products. J Saudi Soc Agric Sci. 2018;17(2):97-106. Available from: 10.1016/j. jssas.2016.01.007.

7. Ramamurthy C, Sampath KS, Arunkumar P, Kumar MS, Sujatha V, Premkumar K. Green synthesis and characterization of selenium nanoparticles and its augmented cytotoxicity with doxorubicin on cancer cells. Bioprocess Biosyst Eng. 2013;36(8):1131-9. PMID: 23446776. Available from: 10.1007/s00449-012-0867-1.

8. Lingaraju K, Naika HR, Manjunath K, Basavaraj R, Nagabhushana $H$, Nagaraju $G$. Biogenic synthesis of zinc oxide nanoparticles using Ruta graveolens (L.) and their antibacterial and antioxidant activities. Appl Nanosci. 2016;6(5):703-10. Available from: 10.1007/s13204-015-0487-6.

9. Bhumi G, Savithramma N. Biological synthesis of zinc oxide nanoparticles from Catharanthus roseus (L.) G. Don. Leaf extract and validation for antibacterial activity. Int J Drug Dev Res. 2014;6(1):208-14.

10. Saleem M, Fang L, Ruan H, Wu F, Huang Q, Xu C. Effect of zinc acetate concentration on the structural and optical properties of $\mathrm{ZnO}$ thin films deposited by Sol-Gel method. Int J Phys Sci. 2012;7(23):2971-9. Available from: 10.5897/IJPS12.219.

11. Dobrucka R, DJ. Biosynthesis and antibacterial activity of $\mathrm{ZnO}$ nanoparticles using Trifolium pratense flower extract. Saudi $J$ Biol Sci. 2016;23(4):517-23. PMID: 27298586. Available from: 10.1016/j.sjbs.2015.05.016.

12. Selvarajan E, Mohanasrinivasan V. Biosynthesis and characterization of $\mathrm{ZnO}$ nanoparticles using Lactobacillus plantarum VITES07. Mater Lett. 2013;112:180-2. Available from: 10.1016/j.matlet.2013.09.020

13. Zak AK, Razali R, Majid WH, Darroudi M. Synthesis and characterization of a narrow size distribution of zinc oxide nanoparticles. Int J Nanomedicine. 2011;6:1399-403. PMID: 21796242.

14. Al-Shabib NA, Husain FM, Ahmed F, Khan RA, Ahmad I, Alsharaeh E. Biogenic synthesis of Zinc oxide nanostructures from Nigella sativa seed: prospective role as food packaging material inhibiting broad-spectrum quorum sensing and biofilm. Sci Rep. 2016;6(1):36761. PMID: 27917856. Available from: $10.1038 /$ srep36761.

15. Parthasarathy G, Saroja M, Venkatachalam M, Evanjelene V. Biological synthesis of zinc oxide nanoparticles from leaf extract of Curcuma neilgherrensis Wight. Int J Mater Sci. 2017;12:7386.

16. Bai DP, Zhang XF, Zhang GL, Huang YF, Gurunathan S. Zinc oxide nanoparticles induce apoptosis and autophagy in human ovarian cancer cells. Int J Nanomedicine. 2017;12:6521-35. PMID: 28919752. Available from: 10.2147/IJN.S140071.

17. Fatoh MFE, Farag MR, Shafika A, Hussein MA, Kamel M, Salem G. Cytotoxic Impact of Zinc Oxide Nanoparticles against Ehrlich Ascites Carcinoma Cells in Mice. Int J Pharma Sci. 2014;4(3):560-4.

18. Eissa LA, Habib SA, Latif MMA. Inhibitory effect of the partially purified protein from Raphnus sativus roots and lowmolecular-weight heparin on Ehrlich ascites carcinoma bearing mice. Egyptian Journal of Basic and Applied Sciences. 2014;1(2):88-96. Available from: 10.1016/j.ejbas.2014.05.002. 
19. Khedr NF, Khalil RM. Effect of hesperidin on mice bearing Ehrlich solid carcinoma maintained on doxorubicin. Tumour Biol. 2015;36(12):9267-75. PMID: 26099723. Available from: 10.1007/s13277-015-3655-0.

20. Young D. Effects of disease on Clinical Lab. Tests. AACC; 2001.

21. Larsen K. Creatinine assay by a reaction-kinetic principle. Clin Chim Acta. 1972;41:209-17. PMID: 4645233. Available from: 10.1016/0009-8981(72)90513-X.

22. Yagi K. Lipid peroxides and human diseases. Chem Phys Lipids. 1987;45(2-4):337-51. PMID: 3319232. Available from: 10.1016/0009-3084(87)90071-5.

23. Beutler E, Duron O, Kelly BM. Improved method for the determination of blood glutathione. J Lab Clin Med. 1963;61:882-8. PMID: 13967893.

24. Beers RF, Sizer IW. A spectrophotometric method for measuring the breakdown of hydrogen peroxide by catalase. J Biol Chem. 1952;195(1):133-40. PMID: 14938361. Available from: 10.1016/S0021-9258(19)50881-X.

25. Rotruck JT, Pope AL, Ganther HE, Swanson AB, Hafeman DG, Hoekstra WG. Selenium: biochemical role as a component of glutathione peroxidase. Science. 1973;179(4073):588-90. PMID: 4686466. Available from: 10.1126/science.179.4073.588.

26. Habig WH, Pabst MJ, Jakoby WB. Glutathione S-transferases. The first enzymatic step in mercapturic acid formation. J Biol Chem. 1974;249(22):7130-9. PMID: 4436300. Available from: 10.1016/S0021-9258(19)42083-8.

27. Pozarowski P, Darzynkiewicz Z. Analysis of cell cycle by flow cytometry. Checkpoint controls and cancer. Springer; 2004.

28. Namvar F, Rahman HS, Mohamad R, Azizi S, Tahir PM, Chartrand MS, et al. Cytotoxic effects of biosynthesized zinc oxide nanoparticles on murine cell lines. Evid Based Complement Alternat Med. 2015;2015. Available from: 10.1155/2015/ 593014.

29. Bradford MM. A rapid and sensitive method for the quantitation of microgram quantities of protein utilizing the principle of protein-dye binding. Anal Biochem. 1976;72(1-2):248-54. PMID: 942051 . Available from: 10.1016/0003-2697(76)905273.

30. Hague A, Díaz GD, Hicks DJ, Krajewski S, Reed JC, Paraskeva C. bcl-2 and bak may play a pivotal role in sodium butyrate-induced apoptosis in colonic epithelial cells; however overexpression of bcl-2 does not protect against bakmediated apoptosis. Int J Cancer. 1997;72(5):898-905. PMID: 9311611. Available from: 10.1002/(SICI)1097-0215(19970904) 72:5<898::AID-IJC30>3.0.CO;2-2.

31. Bancroft JD, Gamble M. Theory and practice of histological techniques. In: Theory and practice of histological techniques. Elsevier health sciences; 2008

32. Valdiglesias V, Costa C, Kiliç G, Costa S, Pásaro E, Laffon B. Neuronal cytotoxicity and genotoxicity induced by zinc oxide nanoparticles. Environ Int. 2013;55:92-100. PMID: 23535050. Available from: 10.1016/j.envint.2013.02.013.
33. Sanaeimehr Z, Javadi I, Namvar F. Antiangiogenic and antiapoptotic effects of green-synthesized zinc oxide nanoparticles using Sargassum muticum algae extraction. Cancer Nanotechnol. 2018;9(1):3. PMID: 29628994. Available from: 10.1186/s12645-018-0037-5.

34. El-Bahy G. FTIR and Raman spectroscopic study of Fenugreek (Trigonella foenum graecum L.) seeds. J Appl Spectrosc. 2005;72(1):111-6. Available from: 10.1007/s10812-005-00406.

35. Elfiky M, Salahuddin N, Matsuda A. Green fabrication of 3D hierarchical blossom-like hybrid of peeled montmorillonite$\mathrm{ZnO}$ for in-vitro electrochemical sensing of diltiazem hydrochloride drug. Mater Sci Eng C. 2020;111:110773. PMID: 32279745. Available from: 10.1016/j.msec.2020.110773.

36. Xia T, Kovochich M, Brant J, Hotze M, Sempf J, Oberley T. Comparison of the abilities of ambient and manufactured nanoparticles to induce cellular toxicity according to an oxidative stress paradigm. Nano Lett. 2006;6(8):1794-807. PMID 16895376. Available from: 10.1021/nl061025k.

37. Hassan HF, Mansour AM, Abo-Youssef AM, Elsadek BE, Messiha BA. Zinc oxide nanoparticles as a novel anticancer approach; in vitro and in vivo evidence. Clin Exp Pharmacol Physiol. 2017;44(2):235-43. PMID: 27718258. Available from: 10.1111/1440-1681.12681.

38. El-Shorbagy HM, Eissa SM, Sabet S, El-Ghor AA. Apoptosis and oxidative stress as relevant mechanisms of antitumor activity and genotoxicity of ZnO-NPs alone and in combination with $\mathrm{N}$-acetyl cysteine in tumor-bearing mice. Int J Nanomedicine. 2019;14:3911-28. PMID: 31213808. Available from: 10.2147/ IJN.S204757.

39. Nabeel Al. Samarium enriches antitumor activity of $\mathrm{ZnO}$ nanoparticles via downregulation of CXCR4 receptor and cytochrome P450. Tumour Biol. 2020;42(3):1010428320909999. PMID: 32129155. Available from: 10.1177/1010428320909999.

40. Carnero A. Targeting the cell cycle for cancer therapy. Br J Cancer. 2002;87(2):129-33. PMID: 12107831. Available from: $10.1038 /$ sj.bjc. 6600458 .

41. Kavithaa K, Paulpandi M, Ponraj T, Murugan K, Sumathi S. Induction of intrinsic apoptotic pathway in human breast cancer (MCF-7) cells through facile biosynthesized zinc oxide nanorods. Karbala International Journal of Modern Science. 2016;2(1):46-55. Available from: 10.1016/j.kijoms.2016.01.002.

42. Sharma V, Anderson D, Dhawan A. Zinc oxide nanoparticles induce oxidative DNA damage and ROS-triggered mitochondria mediated apoptosis in human liver cells (HepG2). Apoptosis. 2012;17(8):852-70. PMID: 22395444. Available from: 10.1007/s10495-012-0705-6.

43. Abosharaf HA, Salah M, Diab T, Tsubaki M, Mohamed TM. Biogenic silver nanoparticles induce apoptosis in Ehrlich ascites carcinoma. Biomed Res Ther. 2020;7(11):4100-13. Available from: 10.15419/bmrat.v7i11.647. 
Ready to submit your manuscript? Choose Biomedpress and benefit from:

- Fast, convenient online submission

- Through peer-review by experienced researchers

- Rapid publication on acceptance

- Free of charge (without publication fees)

Learn more http://www.biomedpress.org/journals/

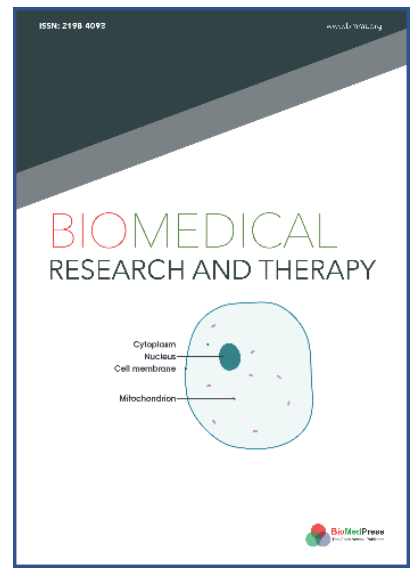

\title{
Biomedical Research and Therapy
}

Indexed: Web of Science (ESCl), Embase, Google Scholar

Journal Citation Indicator (2020): 0.16

Acceptance Rate (2020): 54.32\%

Article Publishing Charge: Free

Submission to first editorial decision: 27 days

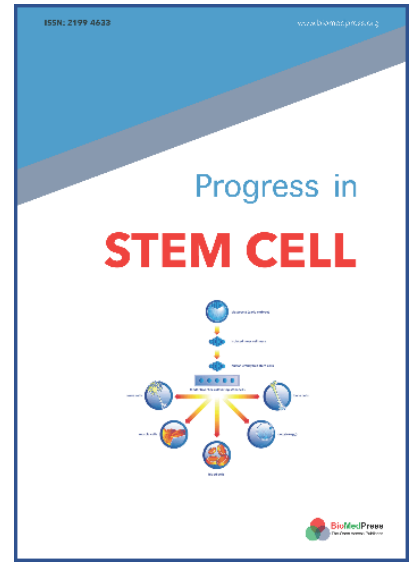

\section{Progress in Stem Cell}

Indexed: Embase, Google Scholar

Acceptance Rate (2020): 78.19\%

Article Publishing Charge: Free

Submission to first editorial decision: 19 days

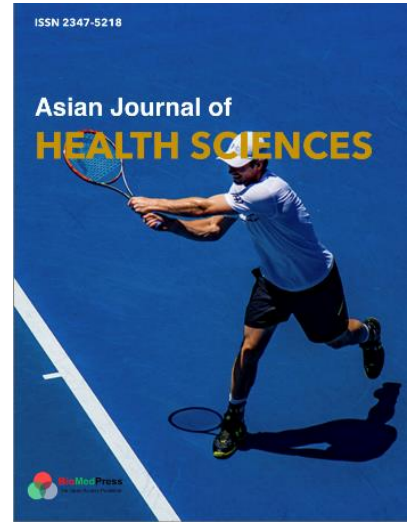

\author{
Asian Journal of Health Sciences \\ Indexed: Google Scholar \\ Acceptance Rate (2020): 72.89\% \\ Article Publishing Charge: Free \\ Submission to first editorial decision: 16.5 days
}

